\title{
Climate change in the rocky intertidal zone: predicting and measuring the body temperature of a keystone predator
}

\author{
P. Lauren Szathmary*, Brian Helmuth, David S. Wethey \\ University of South Carolina, Department of Biological Sciences and Marine Science Program, Columbia, \\ South Carolina 29208, USA
}

\begin{abstract}
Forecasting the responses of populations and ecosystems to climate change requires that we understand both the direct effects of temperature on organism physiology and the indirect effects of temperature change on interactions such as predation and competition. The sea star Pisaster ochraceus is a keystone predator in the rocky intertidal zone with a broad geographic distribution along the west coast of North America. We developed a mechanistic heat budget model that uses environmental data to predict the body temperatures of $P$. ochraceus. Model accuracy was verified by comparing model output temperatures, generated using measured microclimatic data as input, to the temperatures of live $P$. ochraceus in the field. The average absolute errors between predicted and measured body temperatures were $\sim 1^{\circ} \mathrm{C}$. To continuously monitor sea star body temperatures in the field, we developed data loggers that thermally mimic P. ochraceus. Accuracy of these biomimetic loggers was tested by comparing logger temperatures to $P$. ochraceus body temperatures, and they were found to mimic body temperatures within $\sim 1^{\circ} \mathrm{C}$. Loggers were deployed at different tidal heights at a site in Bamfield, British Columbia, Canada, to investigate within-site body temperature variation. We also explored the relationship between body temperature and vertical distribution of $P$. ochraceus. A negative correlation was found between maximum body temperatures on Day $n$ and the number of sea stars found in the intertidal on Day $n+1$. These results suggest that temperatures reached during aerial exposure at low tide, at least in part, may determine where in the intertidal zone these sea stars are located, which could affect their foraging limits.
\end{abstract}

KEY WORDS: Heat budget - Climate change - Intertidal zone - Pisaster ochraceus · Sea star · Temperature logger

Resale or republication not permitted without written consent of the publisher

\section{INTRODUCTION}

Temperature is a key abiotic factor that affects organism distribution, physiological performance, and interspecific interactions (e.g. Southward 1958, Connell 1961, Crisp 1964), and understanding the role of climate in driving patterns of body temperature has become a key focus in the face of global climatic change. In many cases, organisms have been shown to be geographically limited by aspects of climate. In such cases, these species are living at the edges of their fundamental niche spaces (sensu Hutchins 1947, MacArthur 1972, Wethey \& Woodin 2008), and further changes in climate that translate directly into increased levels of physiological stress serve directly to limit their biogeographic range limits. For other species, climate may indirectly limit species range boundaries by changing rates of predation or competition (Wethey $1983,1984,2002)$; in other words, aspects of a species' realized niche space may be altered by direct climatic effects on a consumer or competitor's fundamental niche space, or through effects on the consumer's physiological performance (Sanford 1999, 2002a). In yet other cases, range boundaries may be driven by factors unrelated to climate (e.g. Crisp \& Southward 1958, Mustin et al. 2007). Thus, to quantitatively pre- 
dict ecological responses to climate change, we must be able to forecast how organismal responses to temperature vary in space and time across a cascade of trophic levels and among competing species (Davis et al. 1998a,b). We explore the determinants of body temperature of a keystone predator as an initial first step in comparing levels of physiological stress between predator and prey pairs in the rocky intertidal zone.

The rocky intertidal zone is a model system to examine ecological principles (Connell 1972, Paine 1994), in part because organisms are exposed to steep gradients in physiological stress and because organisms living at the upper edges of these gradients are generally thought to live close to their thermal tolerance limits (Foster 1969, Somero 2002, Davenport \& Davenport 2005). For many rocky intertidal species, upper zonation limits are thought to be set by physical stresses related to body temperature or desiccation (Foster 1971, Connell 1972) experienced during aerial exposure at low tide. Therefore, global climate change is expected to have large effects on intertidal species. Such effects have already been documented in a number of locations (Southward et al. 1995, Sagarin et al. 1999, Helmuth et al. 2006a, Wethey \& Woodin 2008). However, recent studies have emphasized that the determinants of intertidal species range boundaries are often complex, and that our understanding of how patterns of thermal stress vary in space and time is often far from complete. For example, geographic patterns of aerial body temperature are often quite different from patterns of temperature of the surrounding water or air (Helmuth et al. 2002, Gilman et al. 2006). As a result, predictions of thermal stress based on aerial body temperature depict thermal 'mosaic' patterns where animals are most likely to experience thermal damage at a series of hot spots within the species' range, rather than just at range edges (Helmuth et al. 2006a,b, Sagarin \& Somero 2006, Place et al. 2008).

Importantly, as is true for other organisms, the temperature of an intertidal invertebrate's body during low tide is driven by multiple, interacting climatic factors, including solar radiation, wind speed, cloud cover, and air, water, and surface temperatures (Fig. 1). Moreover, the morphology, mass, color, behavior, and surface wetness of an organism can have significant effects on rates of heat exchange, so that 2 ectothermic organisms exposed to identical microclimates can experience markedly different body temperatures. Therefore, how climate drives body temperatures of ectotherms at low tide and how the body temperatures of organisms respond to climate is determined by the organisms' physical properties. In addition, physiological tolerance to body temperature extremes varies among species (Foster 1969, Buckley et al. 2001) and within species from different sites (Stillman 2003).
Physiological rate effects of body temperatures are also species-specific (Southward 1955, Sanford 2002b, Stenseng et al. 2005). Thus, determining responses to climate change requires that we consider the effects of climate on a site-by-site and species-by-species basis, both in terms of physiological responses and in terms of body temperatures (Southward 1955, Stillman 2003, Helmuth et al. 2006a,b).

Given the physiologically and ecologically important role of body temperature, an accurate means of approximating an organism's temperature in the field over a wide range of temporal and spatial scales is extremely useful. Mechanistic heat budget models have been used to predict body temperatures of terrestrial organisms for decades (e.g. Porter \& Gates 1969, Tracy 1976, Kingsolver 1979), and more recently for intertidal species (Bell 1995, Helmuth 1998, Wethey 2002, Denny \& Harley 2006). These models of intertidal species often demonstrate considerable differences between body temperatures and air, surface, and water temperatures, and mechanistically illustrate how the interacting environmental variables contribute to body temperature. When combined with global climate change models, these approaches can further be used to forecast estimates of body temperature and thermal stress under varying scenarios of climate change (e.g. Gilman et al. 2006, Helmuth et al. 2006a).

The application of these models has shown that local variables such as substratum aspect, wave splash, and levels of shading can often have an enormous impact on the body temperature of organisms (Helmuth \& Hofmann 2001, Wethey 2002). The verification of models with in situ instrumentation is therefore crucial, especially when measurements of within-site thermal heterogeneity are required (e.g. Rand et al. 2002).

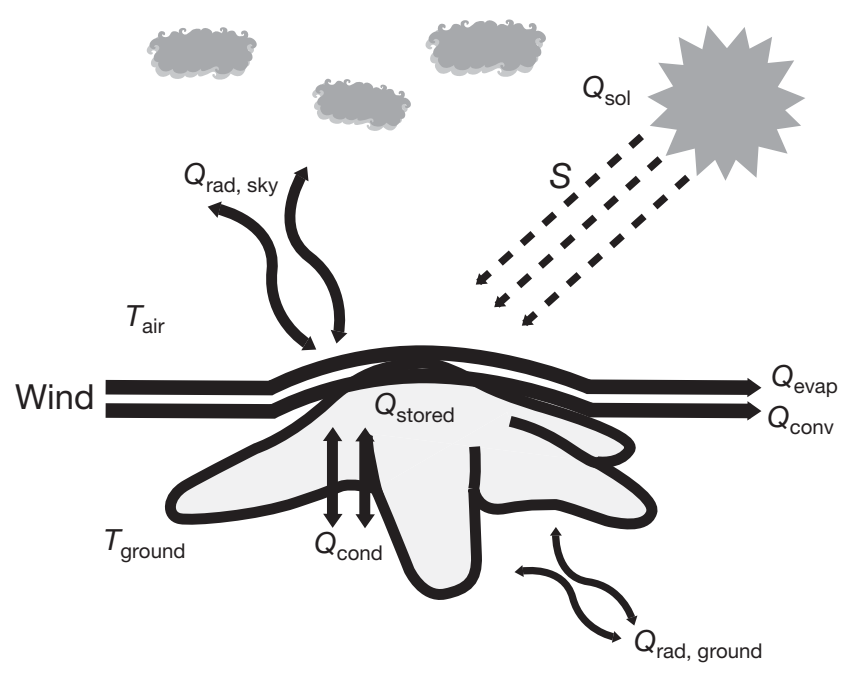

Fig. 1. Schematic representation of determinants of heat flux in a sea star 
Importantly, just as the characteristics of organisms can affect their body temperature, so can the thermal characteristics of temperature loggers and the temperature they record be significantly affected by their mass, shape, and color (Fitzhenry et al. 2004). Biomimetic data loggers that mimic the thermal characteristics of the modeled species are useful tools that can be deployed in various places throughout a site to investigate body temperature variation (Fitzhenry et al. 2004), and they have been used across extensive spatial scales to collect data on the body temperature of intertidal organisms (Helmuth et al. 2002, 2006b). We describe both a mathematical and a biomimetic approach for modeling the body temperature of the sea star Pisaster ochraceus.

\section{MATERIALS AND METHODS}

Study site and organism. Pisaster ochraceus (hereafter Pisaster) is a dominant predator in the intertidal ecosystem (Paine 1966) and, as a keystone species, has an effect on the community structure that is disproportionate to its abundance (Paine 1974). Therefore, understanding the thermal biology of this species and how differential patterns of thermal stress between Pisaster and its prey species are affected by climate is an important step in understanding the functioning of the rocky intertidal ecosystem in the face of climate change. Additionally, Pisaster is a valuable study organism to investigate the effects of small-scale environmental conditions (i.e. microclimate) on body temperature. This species has a broad geographic distribution along the Pacific coast of North America, ranging from Alaska to Baja California (Ricketts et al. 1994), and is thus exposed to a wide variety of climatic and environmental conditions over an extensive latitudinal range.

Changes in body temperature have been shown to affect Pisaster physiology and reliable, broadly applicable means of measuring body temperatures of this species in the field are needed to look at these patterns and their ecological effects on a larger scale. Sanford (2002a) approximated Pisaster body temperature using aerially exposed unmodified data loggers on the ground in the intertidal. Sanford (1999) showed that a slight increase of $3^{\circ} \mathrm{C}$ in water temperature significantly increased the feeding rate of Pisaster. While slight changes in water temperature (and therefore body temperature) had significant physiological effects on Pisaster, the sea stars must endure much greater body temperature fluctuations during aerial exposure at low tide. Pincebourde et al. (2008) showed that chronic exposure ( $>8 \mathrm{~d}$ ) to peak aerial body temperatures $\left(\geq 23^{\circ} \mathrm{C}\right.$ ) caused significantly reduced (30 to $40 \%$ ) feeding rates in Pisaster; in contrast, acute exposure led to increased feeding rates. Thus, temperature can significantly influence predator-prey interaction strength. Pincebourde et al. (2008) also demonstrated that the lethal thermal limit for this species is $35^{\circ} \mathrm{C}$ at their study site. The goal of our project was the development of tools that, when combined with weather and climate data, would allow us to measure and predict when and where Pisaster are experiencing temperatures that are physiologically compromising.

Using a series of field measurements and theoretical (mathematical heat budget) models, we describe temporal patterns of Pisaster body temperature. We developed and tested a mathematical model that allows us to predict mechanistically the body temperatures of these sea stars using terrestrial climatic variables. We also developed and tested biomimetic data loggers to predict and measure Pisaster body temperatures at a site in British Columbia, Canada. We explore the relationship between aerial body temperature and vertical distribution of the sea stars.

We developed a mechanistic heat budget model to account for all inputs, outputs, and stores of heat into Pisaster. The model was modified from a heat flux model presented elsewhere (Gilman et al. 2006). The details of the Pisaster model are provided in Appendix 1 , and values of parameters used in the model are presented in Table 1.

Theoretical model verification. Measured microclimate data: The accuracy of the heat budget model was tested against the aerial body temperatures of live Pisaster in the field. Microclimate data and Pisaster body temperatures were collected for $26 \mathrm{~d}$ during June, July and August 2004. Body temperatures were collected from a total of 114 individuals at various sites around the Bamfield Marine Station in Barkley Sound on the west coast of Vancouver Island, British Columbia, Canada $\left(48^{\circ} 50^{\prime} \mathrm{N}, 125^{\circ} 09^{\prime} \mathrm{W}\right)$. Data were collected at the following sites: Scott's Bay, Kirby Point, Dixon Island, Sandford Island, and Voss Point. Bamfield lies at the approximate latitude at which Pisaster are in greatest abundance (Sagarin \& Gaines 2002), and lowest summer tides at this location generally occur in the morning and early afternoon. Therefore, the sea stars are exposed to aerial conditions for extended periods during daylight hours at these sites.

To collect environmental data, a weather station was set up next to Pisaster in the intertidal zone. The station measured the microclimate adjacent to Pisaster on horizontal surfaces as the tide receded each day, and was picked up when the tide returned. Wind speed was measured using a Kurz 441M anemometer (Kurz Instruments), with the probe positioned about $2.5 \mathrm{~cm}$ above the substratum (roughly the height of the sea stars). Voltage output from the anemometer was recorded and later converted to air velocity in meters 
Table 1. Definitions of model parameters

\begin{tabular}{|c|c|c|c|}
\hline Symbol & Term & Value & Source \\
\hline$\alpha$ & Surface absorptivity & 0.90 & Carrington et al. (unpubl. data) \\
\hline$\varepsilon_{\mathrm{atm}}$ & Emissivity of atmosphere & $\left(0.74+0.0049 v p_{a}\right)\left(1-0.17 \operatorname{ccf}^{2}\right)$ & Tennessee Valley Authority (1972), Idso (1981) \\
\hline$\varepsilon_{\mathrm{s}}$ & Emissivity of surface & 0.75 & \\
\hline$\kappa$ & Thermal diffusivity & $k /\left(\rho_{\mathrm{s}} C_{\mathrm{s}}\right)$ & Holman (1986) \\
\hline$\lambda$ & Latent heat of evaporation & $2.456 \times 10^{3} \mathrm{~J} \mathrm{~g}^{-1}$ & Monteith \& Unsworth (1990) \\
\hline$\rho_{a}$ & Density, air & $1.1774 \times 10^{3} \mathrm{~g} \mathrm{~m}^{-3}$ & Holman (1986) \\
\hline$\rho_{\mathrm{s}}$ & Density, Pisaster (seawater) & $1.025 \times 10^{6} \mathrm{~g} \mathrm{~m}^{-3}$ & Denny (1993) \\
\hline$\sigma$ & Stefan-Boltzmann constant & $5.67 \times 10^{-8} \mathrm{~W} \mathrm{~m}^{-2}{ }^{\circ} \mathrm{K}^{-4}$ & Monteith \& Unsworth (1990) \\
\hline$C_{\mathrm{p}}$ & Specific heat, air & $1.0057 \mathrm{~J} \mathrm{~g}^{-1}{ }^{\circ} \mathrm{K}^{-1}$ & Holman (1986) \\
\hline$C_{\mathrm{S}}$ & Specific heat, Pisaster (seawater) & $4.200 \mathrm{~J} \mathrm{~g}^{-1}{ }^{\circ} \mathrm{K}^{-1}$ & Denny (1993) \\
\hline $\operatorname{ccf}$ & Cloud cover fraction & & Pinker et al. (2003) \\
\hline$h_{\mathrm{c}}$ & Convective heat transfer coeff. & $\rho c_{\mathrm{p}} u K^{2} /\left[\ln \left(z / z_{\mathrm{o}}\right)\right]^{2}$ & Monteith \& Unsworth (1990) \\
\hline$h_{\mathrm{e}}$ & Evaporative heat transfer coeff. & $u K^{2} / \operatorname{Le}^{1 / 3}\left[\ln \left(z / z_{o}\right)\right]^{2}$ & Monteith \& Unsworth (1990) \\
\hline$K$ & von Karman's constant & 0.4 & Monteith \& Unsworth (1990) \\
\hline \multirow[t]{3}{*}{$k$} & Thermal conductivity, & & \\
\hline & Pisaster & $0.6 \mathrm{~W} \mathrm{~m}^{-1}{ }^{\circ} \mathrm{K}^{-1}$ & \\
\hline & Rock & $2.1 \mathrm{~W} \mathrm{~m}^{-1}{ }^{\circ} \mathrm{K}^{-1}$ & Holman (1986) \\
\hline Le & Lewis number & $(\mathrm{Sc} / \mathrm{Pr})^{0.333}$ & Monteith \& Unsworth (1990) \\
\hline $\operatorname{Pr}$ & Prandtl number & 0.708 & Holman (1986) \\
\hline$q_{\text {solar }}$ & Solar radiation & $\mathrm{W} \mathrm{m}^{-2}$ & Directly measured \\
\hline rh & Relative humidity & $\%$ & Directly measured \\
\hline$R_{\mathrm{v}}$ & $\begin{array}{l}\text { Specific gas constant, } \\
\text { Water vapor }\end{array}$ & $0.461 \mathrm{~J} \mathrm{~g}^{-1}{ }^{\circ} \mathrm{K}^{-1}$ & Monteith \& Unsworth (1990) \\
\hline Sc & Schmidt number & 0.60 & Holman (1986) \\
\hline$T_{\text {air }}$ & Air temperature & ${ }^{\circ} \mathrm{K}$ & Directly measured \\
\hline$T_{\mathrm{s}}$ & Surface temperature & ${ }^{\circ} \mathrm{K}$ & Model output \\
\hline$\Delta t$ & Model time step & $10 \mathrm{~s}$ & \\
\hline$u$ & Wind speed & $\mathrm{m} \mathrm{s}^{-1}$ & Directly measured \\
\hline $\mathrm{vp}_{\text {air }}$ & Water vapor pressure, air & $(\mathrm{rh} / 100) \times 611.0 \mathrm{e}^{[(\lambda / R \mathrm{v})(1 / 273-1 / \text { Tair })]}$ & Monteith \& Unsworth (1990) \\
\hline $\mathrm{vp}_{\mathrm{s}}$ & Water vapor pressure, surface & $611.0 \mathrm{e}^{((\lambda / R \mathrm{v})(1 / 273-1 / T \mathrm{~s}))}$ & Monteith \& Unsworth (1990) \\
\hline$z$ & Wind speed observation height & $0.025 \mathrm{~m}$ & Directly measured \\
\hline$\Delta z$ & Model layer thickness & $0.01 \mathrm{~m}$ & \\
\hline$z_{0}$ & Roughness height & $0.005 \mathrm{~m}$ & Monteith \& Unsworth (1990) \\
\hline
\end{tabular}

per second. On days when converted wind speed was $<0.1 \mathrm{~m} \mathrm{~s}^{-1}$, wind speed was assumed to be $0.1 \mathrm{~m} \mathrm{~s}^{-1}$ (as a result of errors in the polynomial conversion equation of voltage to wind speed at very low voltage outputs). Solar radiation was measured using a silicon cell pyranometer (LI-COR) positioned level on the substratum. Relative humidity was recorded using a HOBO Pro RH data logger (Onset Computer Corp.). Air temperature and body temperatures of up to 5 individuals were measured using copper-constantan thermocouples. Body temperatures of Pisaster that were within a $\sim 1 \mathrm{~m}$ radius of the weather station and which were solitary (i.e. not in mats or clusters) and in growth position on flat, horizontal rocks were measured. To measure body temperatures, the thermocouple wires were inserted $\sim 1 \mathrm{~cm}$ deep in the aboral side off-center in the disc, to ensure that internal body temperature was measured, rather than possibly poking through the mouth and into an air pocket underneath the sea star. Outputs from the pyranometer and thermocouples were recorded by a CR10X data logger (Campbell Scientific). All microclimatic variables and body temperatures were recorded every minute. Data collection began after the sea stars were exposed by the receding tide and continued until the tide returned and submerged the sea stars.

Other environmental data were assembled from datasets collected by National Oceanic and Atmospheric Administration (NOAA) satellites and from local weather stations. Water temperature was estimated using NOAA CoastWatch sea surface temperature (SST) satellite data (NOAA 2005). CoastWatch reports average SST over $2 \mathrm{wk}$ periods for the summer, and these average temperatures were used for the corresponding dates in the model. Cloud cover data were generated by a model that uses a modified version of the GEWEX SRB algorithm, which uses data from the NOAA GOES 8 satellite to approximate the fraction of cloud cover from 0 to 1 over $1^{\circ}$ pixels (Pinker et al. 2003). Data were calculated every hour during daylight hours. The data used in the present study were from the pixel at $49^{\circ} \mathrm{N}, 125^{\circ} \mathrm{W}$, and the hourly cloud fraction values were entered into the model for every minute of the corresponding hour.

Operation of the model is detailed in Appendix 1. The model requires appropriate spin-up time with 
environmental data to generate accurate predictions. Because of issues associated with spin-up time and the necessity of recording microclimate data only during low tide, the model was tested in 2 ways. On any given day, there was a delay before instrumentation could be deployed in the intertidal zone. As a result, there was a period of time (lead time) during which microclimate data were recorded, but the animal was aerially exposed and was, therefore, heating. This period varied from $12 \mathrm{~min}$ to $>3 \mathrm{~h}$. During this period (calculated based on tide tables), data from the first time step of actual microclimate measurements were used to fill in missing microclimate data. Thus, the model was run using actual values of tidal exposure in order to simulate a scenario where initial Pisaster temperature conditions were based on water temperature and the initial trajectory was estimated because of missing microclimate data. Second, the model was tested by altering the output so that the initial conditions matched the measured Pisaster temperatures. The second test was performed to determine the accuracy of the trajectory of the model output. Details concerning the data assimilation process used to conduct the second test are given in Appendix 1.

The model was verified by comparing the predicted body temperatures against the measured Pisaster body temperatures from the field (Fig. 2). For the purposes of comparison, an average temperature was calculated from all replicate Pisaster in the field. Average absolute error (the average of absolute values of the differences between model and Pisaster temperatures), average error (the average of the differences between model and Pisaster temperatures), absolute maximum error (the absolute value of the maximum difference between model and Pisaster temperatures), and root mean square error (RMSE) were calculated from theoretical model output temperatures and measured Pisaster temperatures. Calculations were performed with raw data and for daily maxima. Daily maxima were calculated using extreme values and values screened with a 30 min filter. The filtered temperatures were maximum temperatures that were maintained or exceeded for a period of $30 \mathrm{~min}$ (Fitzhenry et al. 2004). Temperatures maintained for $30 \mathrm{~min}$ are thought to be potentially significant because the animals have been experiencing these temperatures for a long enough period to suffer physiological consequences (Fitzhenry et al. 2004). Durbin-Watson statistics were calculated to test for temporal autocorrelation in all observedpredicted comparisons. For autocorrelated data comparisons (all raw data), correlation statistics $(\Phi)$ were calculated by fitting a generalized least squares regression model of the observations to the predictions with an autocorrelated error structure. For data that did not exhibit autocorrelation (all daily maxima com-

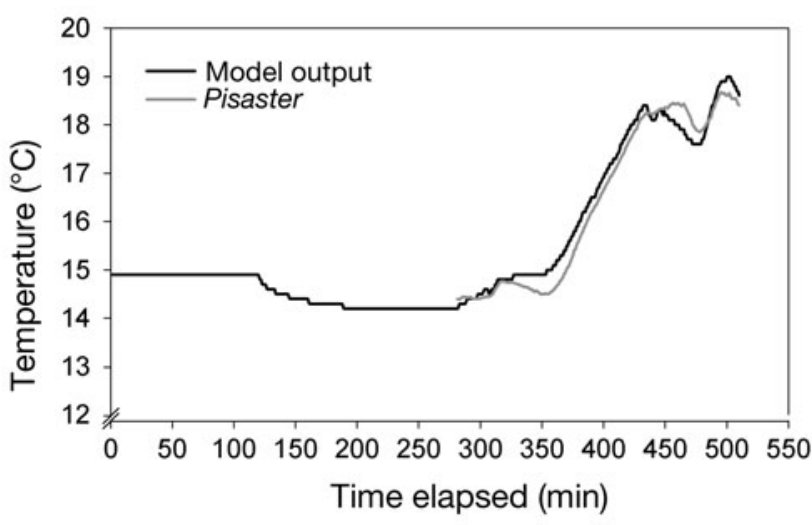

Fig. 2. Theoretical model output and average measured Pisaster body temperatures over time on 16 July 2004. Flat line: model temperature during first $2 \mathrm{~h}$ of Pisaster temperature at high tide. Pisaster are exposed by the receding tide at $t=120 \mathrm{~min}$, and actual Pisaster temperature data start at $t=282 \min$

parisons), a simple linear regression model was used to determine correlation. The model generated temperature predictions from the time of Pisaster exposure when the tide receded until the incoming tide began to wash over the sea stars. The analysis was performed for both uncorrected and corrected model output temperatures.

Biomimetic data logger. A biomimetic data logger that thermally mimicked Pisaster was developed to approximate and record body temperatures in the field. Solid discs of foam with a height of 3.7 and a diameter of $8.5 \mathrm{~cm}$ were carved from Aquazone single-cell foam (Reilly Foam Corp.). Ibutton temperature loggers (Dallas Semiconductor) were implanted into the centers of the discs and continuously recorded temperature to the nearest $0.5^{\circ} \mathrm{C}$ at $5 \mathrm{~min}$ intervals during July and August 2004. These thermal mimics were attached to horizontal rock faces using epoxy putty (Z-spar splash zone epoxy). The accuracy of the mimics was tested by moving 1,2 or, in one case, 4 Pisaster next to each logger soon after exposure at low tide and simultaneously recording Pisaster body temperature and thermal mimic temperature until the tide returned and began to wash over the models and Pisaster. Sea stars that appeared to be of a similar size to the model were selected; end masses ranged from 134 to $257 \mathrm{~g}$. Pisaster body temperatures were recorded using StowAway XTI (thermistor) temperature loggers or Telatemp (thermocouple) temperature loggers (Onset Computer Corp. and Telatemp Corp.). As above, correlations, average, and maximum absolute differences and average difference between Pisaster temperature and logger temperature using raw data, filtered, and unfiltered daily maxima were calculated to verify logger accuracy. The 30 min filter was again used to calculate errors 
in daily maxima in the biomimetic data loggers. On days when 2 or more Pisaster were situated next to a logger, pseudoreplication was taken into account by averaging the temperatures of individuals associated with each logger. Temperatures from 19 pairs of live sea stars and biomimetic loggers were compared. Additionally, theoretical model temperatures generated using microclimate data were compared to biomimetic logger temperatures. These errors were compared against the errors of the model predictions of live sea star temperatures to examine whether Pisaster use active temperature regulation mechanisms that were not accounted for in the model. Only temperature data from the low intertidal loggers were used in this comparison because the other loggers were located higher in the intertidal zone than the microclimate station. Thus, complete microclimate datasets were not available for the full duration of low tide at these higher logger sites, so it was not possible to compare daily maxima. Using the loggers located at mid- and high-intertidal sites in the comparison also would have considerably increased the period of lead time for each day, thus introducing greater potential for error.

Comparison of different methods of predicting Pisaster body temperatures. To compare the accuracy of various methods for estimating Pisaster body temperature, we compared the relationship between measured body temperature and NOAA buoy air temperature, microclimate air temperature, theoretical model temperature, and biomimetic data logger temperature. In other words, we asked whether theoretical models and biomimetic loggers are necessary for predicting animal temperatures in the field, or whether buoy air temperatures are adequate for estimating sea star body temperatures. Statistics calculated for each method varied according to the sampling frequency of the data collected. Buoy air temperatures were obtained from the oceanic buoy nearest to Bamfield, the NOAA Environment Buoy 46206 (48 50' N, $126^{\circ} \mathrm{W}$ ). This buoy records air temperature every hour, so all errors incurred by using buoy air temperature as a proxy for Pisaster body temperature were calculated hourly. Microclimate air temperature and unfiltered theoretical model output temperature accuracies were calculated every minute, and unfiltered biomimetic data logger accuracy was calculated every $5 \mathrm{~min}$. Unfiltered errors were used in the comparison because of the impossibility of filtering $30 \mathrm{~min}$ temperature durations from hourly buoy data. The Durbin-Watson statistic was again calculated for each comparison to test for autocorrelation, and the appropriate correlation statistic was then used $\left(\mathrm{R}^{2}\right.$ or $\left.\Phi\right)$.

Differences in body temperature at different tidal heights. The biomimetic data logger prototypes were deployed at 3 different tidal heights at Scott's Bay and were left to record temperatures at intervals of $5 \mathrm{~min}$ for periods of $2 \mathrm{wk}$ (low models) to $5 \mathrm{wk}$ (middle and high models). Two loggers were deployed at the lowest tidal height of $1.29 \mathrm{~m}$ above the Canadian tide datum of lower low water large tide (LLWLT), and 1 logger each was deployed at the middle and high tidal heights of 1.63 and $2.36 \mathrm{~m}$ above LLWLT. The $30 \mathrm{~min}$ filter on daily maxima (the 98th percentile of data in continuous datasets) and on daily minima (2nd percentile of data in continuous datasets) was applied to each model, and temperatures were compared (Fitzhenry et al. 2004).

Relationship between body temperature and vertical distribution. To investigate how body temperature and thermal history relate to vertical distribution, Pisaster abundances along horizontal transects at different tidal heights were counted and correlated with average maximum Pisaster body temperatures at time lags of 0,1 , and $2 \mathrm{~d}$. Different time lags were used because Pisaster are inactive during low tide (Robles et al. 1995), so high body temperatures experienced at low tide were hypothesized to impact where Pisaster are found in the intertidal on subsequent days.

At a fairly uniformly steep sloping section of Scott's Bay, four $22 \mathrm{~m}$ horizontal transects were laid at 4 different tidal heights $(0.93,1.52,1.96$, and $2.64 \mathrm{~m}$ above LLWLT) that spanned the zone in which Pisaster are generally found. Tidal heights were measured using a surveyor's laser level, and these heights were referenced to a permanent marker with a known tidal height. Tidal heights of the transects were measured every meter along each transect, and the averages of these tidal heights were calculated to determine the overall heights of each transect. Pisaster abundances along all transects were counted on $13 \mathrm{~d}$ from 15 July to 2 August 2004. All Pisaster with $>50 \%$ of their bodies within $0.5 \mathrm{~m}$ above or below each transect line were counted, and transects were $1 \mathrm{~m}$ apart so each transect belt met but did not overlap. Where Pisaster formed high-density mats (mostly in the lowest transect), the sea stars had to be removed from the rocks to obtain accurate counts. After counting, the sea stars were replaced on the rocks where they were found. Data were analyzed using raw daily Pisaster counts and, in the event that sampling inadvertently caused the loss of Pisaster, data were also analyzed daily as a percent of Pisaster remaining from one day to the next. If handling caused the sea stars to move away from the site, a constant decline in abundances would have been expected. However, it is unlikely that the sampling technique caused loss of Pisaster because for 2 runs of $3 \mathrm{~d}$ each during the $2 \mathrm{wk}$ sampling period, Pisaster abundances increased at the lowest transect, 
where most of the sea star removal and replacement was necessary, and there was no trend of decrease in Pisaster abundances along this transect over the course of the sampling period. Additionally, Paine (1976) found that transplanted Pisaster tend to stay in the area to which they have been moved for at least a few months. Therefore, because all sampling was done in a short $2 \mathrm{wk}$ period, the sampling technique of removing some Pisaster from the rocks and replacing them was assumed not to cause migration from the site or affect Pisaster movement within the site. Body temperatures of 3 to 5 haphazardly selected horizontally situated Pisaster were recorded each day during low tide using StowAway and Telatemp temperature loggers. Average maximum body temperatures were calculated for each day and were correlated with counts of Pisaster along transects on the next day. Also, percent change in average maximum body temperature from Day $n$ to Day $n+1$ was correlated with percent change in total numbers of Pisaster counted from Day $n$ to Day $n+1$.
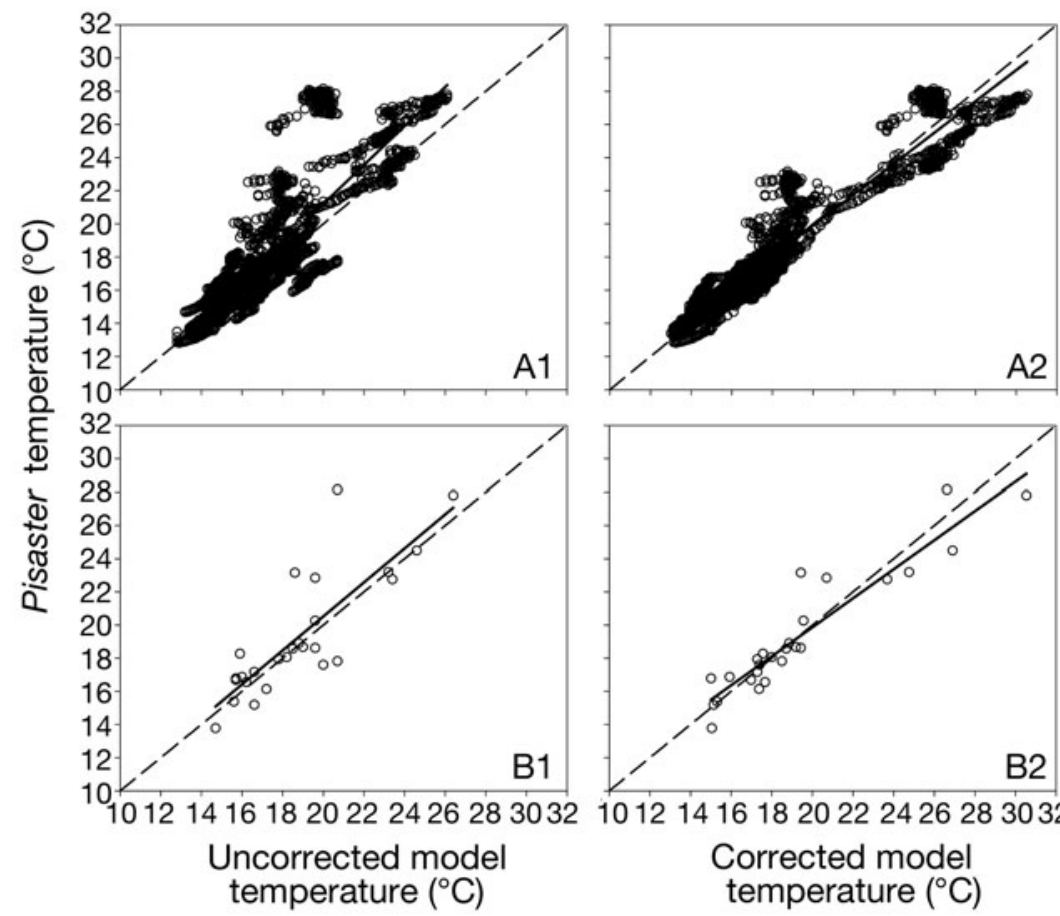

Fig. 3. Average measured Pisaster temperature versus model output temperature. Panels A1 and B1 show uncorrected model output data. Panels A2 and B2 show corrected model output data. Top panels (A1 and A2) show data from each time step; bottom panels (B1 and B2) show daily maximum model and Pisaster temperatures. Dashed line in each graph represents the 1:1 line; solid line is the regression line

\section{RESULTS}

\section{Model verifications}

Theoretical model

The model output temperatures were very similar to average Pisaster body temperatures on most days (Fig. 3). The average absolute error for the theoretical model across all time steps (data recorded every minute) was $\sim 1^{\circ} \mathrm{C}$. The negative average error shows that the model, on average, underestimated Pisaster body temperatures (Table 2). The RMSE was $1.90^{\circ} \mathrm{C}$. Average Pisaster body temperature and model output temperature were highly correlated $(\Phi>0.999$; Table 2). When initial conditions were set to those of recorded aerial body temperature, errors were reduced even further (RMSE: $1.02^{\circ} \mathrm{C}_{i}$ Table 2), which suggests that much of the error in the unadjusted model output could be attributed to discrepancies in the initial trajectory of Pisaster temperatures at the beginning of the low tide period.

Average absolute error of filtered (30 min) daily maxima for the $26 \mathrm{~d}$ of data was $1.46 \pm 1.81^{\circ} \mathrm{C}$ and average error was $-0.76 \pm 2.21$. The RMSE was $2.30^{\circ} \mathrm{C}$. There was a significant correlation between filtered average daily maximum Pisaster body temperature and filtered daily maximum model temperature $\left(\mathrm{p}<0.0001, \mathrm{R}^{2}=\right.$ 0.65; Fig. 3B1, B2). The maximum absolute error was $8.59^{\circ} \mathrm{C}$. When the $30 \mathrm{~min}$ filter was removed, errors were smaller (RMSE: $2.13^{\circ} \mathrm{C} ;$ Table 2). When the initial temperature correction was performed on unfiltered data, errors were smaller and correlation was greater than before the correction (RMSE: 1.37; Table 2).

\section{Biomimetic data logger}

The biomimetic data logger temperatures were also very similar to Pisaster temperatures (Table 2). Average Pisaster body temperature and biomimetic data logger temperature across all time steps were highly correlated $(\Phi=0.930$; Table 2). Average absolute error of daily maxima for the 19 pairs of Pisaster and biomimetic data loggers was $0.93 \pm 0.86^{\circ} \mathrm{C}_{i}$ average error was $-0.93 \pm 0.86^{\circ} \mathrm{C}$. These errors are identical in magnitude because the biomimetic data loggers consistently underestimated Pisaster temperatures for each daily maximum with the 30 min filter (i.e. all errors were negative). There was a significant correlation be- 
Table 2. Average error and average absolute error ( $\pm 1 \mathrm{SD})$, maximum absolute error, and $\Phi$ or $\mathrm{R}^{2}$ for all time steps and unfiltered daily maxima for predicting Pisaster body temperatures using buoy air temperature data from NOAA Environment Buoy 46206, microclimate air temperature, theoretical model output temperature, and biomimetic data logger temperature

\begin{tabular}{|c|c|c|c|c|c|c|c|c|}
\hline & \multirow[b]{2}{*}{$\begin{array}{c}\text { Average } \\
\text { error } \\
\pm 1 \mathrm{SD}\left({ }^{\circ} \mathrm{C}\right)\end{array}$} & \multirow[b]{2}{*}{$\begin{array}{l}\text { All time ster } \\
\text { Average } \\
\text { absolute error } \\
\pm 1 \mathrm{SD}\left({ }^{\circ} \mathrm{C}\right)\end{array}$} & \multirow[b]{2}{*}{$\begin{array}{l}\text { Max. } \\
\text { absolute } \\
\text { error }\left({ }^{\circ} \mathrm{C}\right)\end{array}$} & \multirow[b]{2}{*}{$\Phi$} & \multirow[b]{2}{*}{$\begin{array}{c}\text { Average } \\
\text { error } \\
\pm 1 \mathrm{SD}\left({ }^{\circ} \mathrm{C}\right)\end{array}$} & \multirow{2}{*}{$\begin{array}{l}\text { Daily maxima } \\
\text { Average } \\
\text { absolute error } \\
\pm 1 \mathrm{SD}\left({ }^{\circ} \mathrm{C}\right)\end{array}$} & \multirow[b]{2}{*}{$\begin{array}{l}\text { Max. } \\
\text { absolute } \\
\text { error }\left({ }^{\circ} \mathrm{C}\right)\end{array}$} & \multirow[b]{2}{*}{$\mathrm{R}^{2}$} \\
\hline & & & & & & & & \\
\hline Buoy air $T$ & $-3.56 \pm 3.50$ & $3.67 \pm 3.38$ & 12.81 & 0.683 & $-3.40 \pm 3.60$ & $3.99 \pm 2.90$ & 10.85 & 0.09 \\
\hline Microclimate air $T$ & $-1.62 \pm 2.16$ & $1.76 \pm 2.04$ & 10.27 & $>0.999$ & $-1.23 \pm 2.03$ & $1.68 \pm 1.66$ & 6.97 & 0.68 \\
\hline $\begin{array}{l}\text { Theoretical model: } \\
\text { uncorrected }\end{array}$ & $-0.61 \pm 1.79$ & $1.10 \pm 1.55$ & 8.77 & $>0.999$ & $-0.49 \pm 2.11$ & $1.34 \pm 1.68$ & 7.44 & 0.68 \\
\hline $\begin{array}{l}\text { Theoretical model: } \\
\text { corrected }\end{array}$ & $-0.06 \pm 1.02$ & $0.70 \pm 0.75$ & 5.11 & $>0.999$ & $0.05 \pm 1.40$ & $1.02 \pm 0.94$ & 3.72 & 0.88 \\
\hline $\begin{array}{l}\text { Biomimetic data } \\
\text { logger }\end{array}$ & $-0.64 \pm 1.10$ & $0.86 \pm 0.93$ & 7.35 & 0.930 & $-0.62 \pm 0.60$ & $0.72 \pm 0.47$ & 2.02 & 0.97 \\
\hline
\end{tabular}

tween filtered average daily maximum Pisaster body temperature and filtered daily maximum logger temperature $\left(\mathrm{p}<0.0001, \mathrm{R}^{2}=0.94\right)$. The maximum $\mathrm{ab}$ solute error was $3.84^{\circ} \mathrm{C}$. When the $30 \mathrm{~min}$ filter was removed, errors were smaller and not all daily maxima were underestimated by the biomimetic data loggers (Table 2). Theoretical model temperature and biomimetic data logger temperature across all time steps were highly correlated $(\Phi=0.990)$, and the associated errors were similar to those of the model predictions of live Pisaster temperatures (average absolute error: $0.71 \pm 0.52^{\circ} \mathrm{C}$, average error: $-0.41 \pm 0.78^{\circ} \mathrm{C}$, maximum absolute error: $2.45^{\circ} \mathrm{C}$ ). Average absolute error of unfiltered daily maxima was $1.15 \pm 0.54^{\circ} \mathrm{C}$, average error was $-0.43 \pm 1.35^{\circ} \mathrm{C}$, and maximum absolute error was $1.75^{\circ} \mathrm{C}\left(\mathrm{p}=0.12, \mathrm{R}^{2}=0.78, \mathrm{n}=4\right)$.

\section{Comparison of different methods of predicting Pisaster body temperature}

A summary of errors for each of the different ways to predict Pisaster body temperatures (buoy air temperature, microclimate air temperature, theoretical model temperature, and biomimetic data logger temperature) is presented in Table 2. Errors from the corrected theoretical model output show that the theoretical model is the best method of predicting Pisaster body temperatures across all time steps, followed closely by the biomimetic data loggers. Both models have average absolute errors within $1^{\circ} \mathrm{C}$ across all time steps, suggesting that they are both excellent at following the thermal history of Pisaster in the field. The biomimetic data loggers are the best means to approximate daily maxima, followed closely by the corrected theoretical model. Both of these models also have average absolute errors at or below $1^{\circ} \mathrm{C}$ for daily maxima. Uncorrected and corrected theoretical model output and biomimetic data logger temperatures have lower errors and greater correlations with actual Pisaster temperatures than either microclimate or meteorological buoy air temperatures. In contrast, the average difference between microclimate air temperature and Pisaster temperature $\left(1.62^{\circ} \mathrm{C}\right)$ was almost 3 times the difference between animal temperature and either modeled $\left(0.61^{\circ} \mathrm{C}\right)$ or measured $\left(0.64^{\circ} \mathrm{C}\right)$ body temperature (Table 2). The average difference between meteorological buoy air temperature and Pisaster temperature $\left(3.56^{\circ} \mathrm{C}\right)$ was 6 times the difference between modeled or measured body temperature (Table 2). This result indicates that the model and the loggers are dramatically better estimators of Pisaster temperature than meteorological air temperature.

\section{Differences in body temperature at different tidal heights}

Fig. 4 shows time series data from the biomimetic data loggers over a subset of days recorded. During early morning low tides, logger temperatures decreased during aerial exposure, whereas they increased during afternoon low tides. Differences of up to $9^{\circ} \mathrm{C}$ between the high intertidal and the low intertidal loggers were observed on some warm days. On some days, the mid-intertidal logger temperatures were closer to those of the high intertidal logger; on other days, the mid-intertidal logger temperatures were closer to those of the low intertidal logger. Daily minima were similar across all loggers for each day, but daily maxima differed considerably (Fig. 5). On nearly half of the days, the high intertidal logger recorded temperatures $>25^{\circ} \mathrm{C}$. Almost all of the daily minima for all loggers were below sea surface temperature $\left(\sim 15^{\circ} \mathrm{C}\right)$. Overall, the high intertidal logger always reached the highest daily maximum temperatures, and the low intertidal loggers always reached the lowest. 


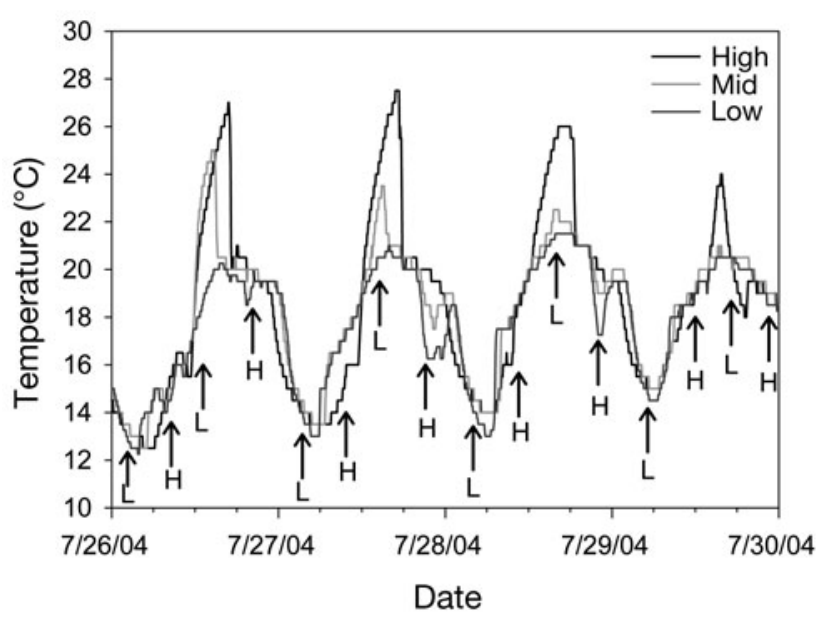

Fig. 4. Biomimetic data logger temperatures at 3 tidal heights (high $=2.36 \mathrm{~m}$ above LLWLT, mid $=1.63 \mathrm{~m}$ above LLWLT, low $=1.29 \mathrm{~m}$ above LLWLT) from Scott's Bay, Bamfield, Canada, 26 to 29 July 2004. Major tick marks are at 0:00 h local time. Approximate times of high tide $(\mathrm{H})$ and low tide (L) are shown. A subset of days from the overall dataset is represented. Date given as M/DD/YY

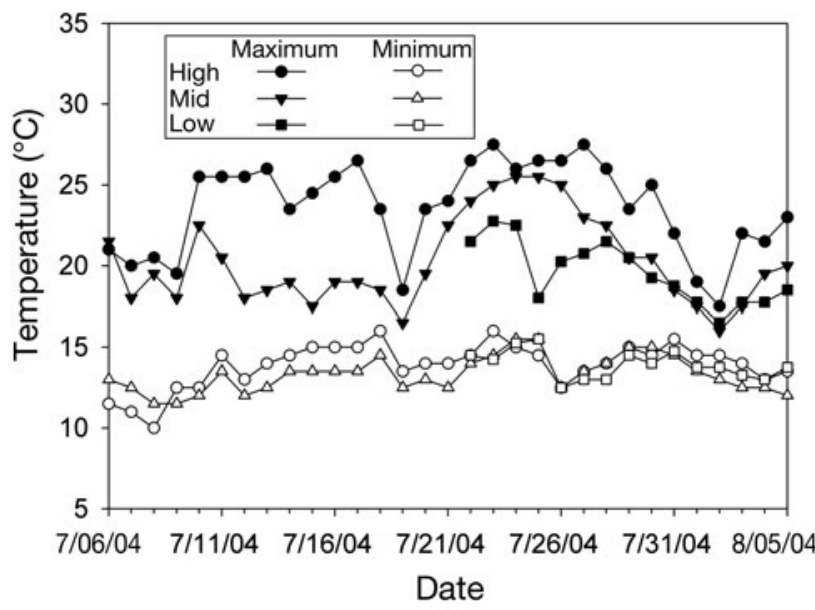

Fig. 5. Daily maximum with a 30 min filter (98th percentile of temperatures; represented by closed symbols) and daily minimum with a 30 min filter (2nd percentile of temperatures; open symbols) of biomimetic data logger temperatures at 3 tidal heights at Scott's Bay, Bamfield, British Columbia, Canada, in summer 2004. Date given as M/DD/YY

\section{Relationship between body temperature and vertical distribution}

No significant correlation was found between the total number of Pisaster counted and average daily maximum Pisaster body temperature for time lags of 0 and $2 \mathrm{~d}\left(\mathrm{R}^{2}=0.199, \mathrm{p}=0.1265\right.$ and $\mathrm{R}^{2}=0.0427, \mathrm{p}=$ 0.5667 , respectively). While none of the correlations between number of Pisaster counted on any individual transect and average maximum Pisaster body temperature were significant, there was a significant negative correlation between total number of Pisaster counted along all transects on Day $n+1$ and maximum Pisaster body temperature on Day $n\left(y=-20.606 x+693.27 ; \mathrm{R}^{2}=\right.$ 0.4712; p =0.0284; Fig. 6).

\section{DISCUSSION}

\section{Accuracy of model and loggers}

Body temperatures significantly affect organism physiology and interspecific interactions in the rocky intertidal zone. The heat budget model developed in this study has an average absolute error of $\sim 1^{\circ} \mathrm{C}$, and is an important step in predicting patterns of body temperature, and hence patterns of stress and performance, for a keystone intertidal predator. Previous measurements of maximum Pisaster body temperatures during low tide had an accuracy of \pm 2 to $3^{\circ} \mathrm{C}$ using unmodified data loggers (Sanford 2002a), but because small differences (e.g. $3^{\circ} \mathrm{C}$ ) in Pisaster body temperature can significantly affect their physiology (Sanford 1999, Pincebourde et al. 2008), such errors may be too great to capture physiologically significant variability in body temperatures during low tide. Also, Pisaster body temperatures had a diurnal range of $\sim 13^{\circ} \mathrm{C}$ during low tide on hot days in this study, so an error of $3^{\circ} \mathrm{C}$ is nearly $25 \%$ of the observed range of temperatures Pisaster experience, which constitutes a relatively large error. Interestingly, the microclimate air temperatures measured in this study had smaller average absolute errors than those observed in unmodified, aerially exposed loggers (Sanford 2002a). Microclimate air temperature in the present study was measured with a thermocouple wire suspended $\sim 5 \mathrm{~cm}$

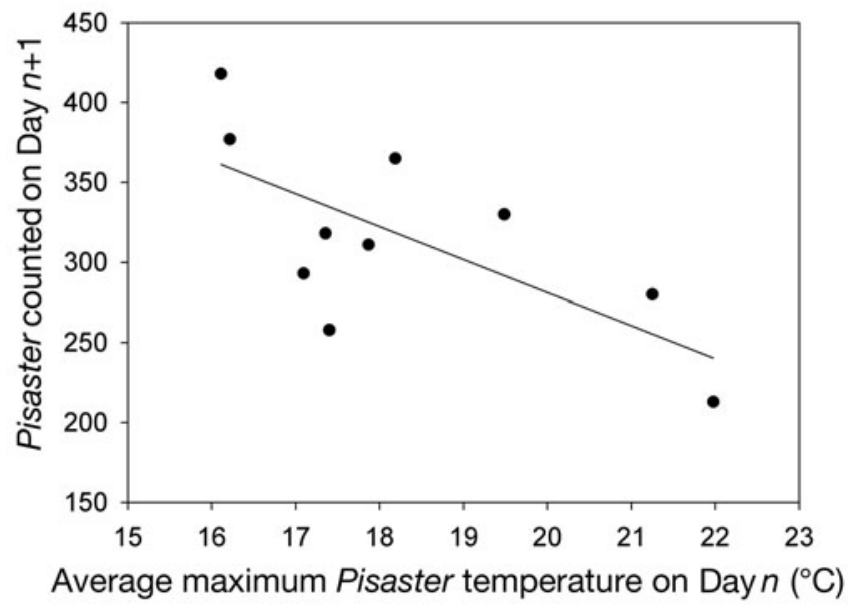

Fig. 6. Total number of Pisaster counted along all transects on Day $n+1$ versus average maximum Pisaster body temperature on Day $n$. Correlation was significant $(y=-20.606 x+$ 693.27; $\left.\mathrm{R}^{2}=0.4712 ; \mathrm{p}=0.0284\right)$ 
above the rock surface; therefore, it was at the appropriate spatial scale for estimating convective heat exchange. Even so, microclimate air temperature underestimated Pisaster body temperature by nearly $2^{\circ} \mathrm{C}$ on average, and if air temperature had been measured at a height $>5 \mathrm{~cm}$, the error would have likely been greater, as shown by the error reflected in buoy air temperatures. In addition, with maximum errors of $>10^{\circ} \mathrm{C}$ (Table 2), using air temperature as a proxy for body temperature has the potential to overlook thermally stressful temperatures. The results of the present study show that the use of biophysical heat budget models and biomimetic sensors provide a clear advantage over the use of air temperatures for predicting sea star body temperatures, particularly when estimating extreme temperatures.

Although the errors found in the theoretical model before the initial temperature correction show that the model is likely an adequate predictor of Pisaster body temperatures, results suggest that if continuous weather data were available, the model accuracy would probably improve. Because the microclimate weather station had to be set up daily, this inevitably resulted in the missed lead time data values. If those data were available, the initial temperatures of the model and the measured Pisaster would likely be much more comparable. This shortcoming in the way the model had to be run is likely the source of much of the error; however, in spite of these problems, the theoretical model was a good predictor of Pisaster body temperatures. In the future, this model will incorporate larger scale meteorological data as input, negating the necessity of collecting microclimate data.

The errors in the Pisaster theoretical model were comparable with those in the theoretical heat budget models of other rocky intertidal species. Helmuth $(1998,1999)$ found an average error of $\sim 1^{\circ} \mathrm{C}$ in his model of Mytilus californianus, and Wethey (2002) found an average error of $2^{\circ} \mathrm{C}$ in the model he developed to approximate the body temperatures of the barnacles Chthamalus fragilis and Semibalanus balanoides by calculating rock temperature. The similar magnitudes of the errors make these models a good means to compare body temperatures of the different species in the intertidal.

The biomimetic data loggers were excellent mimics of Pisaster body temperature, and they were the best method of monitoring daily maxima on average (see average absolute error in Table 2). The loggers developed in this study had an average absolute error of $<1^{\circ} \mathrm{C}$, which improved on an average error of \pm 2 to $3^{\circ} \mathrm{C}$ of previous loggers (Sanford 2002a). However, the biomimetic loggers did tend to slightly underestimate Pisaster body temperatures overall, although maximum error in filtered daily maxima was small $\left(<4^{\circ} \mathrm{C}\right)$. This slight underestimation could be caused by the color of the models. The models were white, whereas Pisaster's colors range from orange to purple. The short-wave absorptivity of the models was probably lower than that of Pisaster, as white is a more reflective color. Even so, the current design yielded excellent results. The accuracy of the theoretical model predictions of biomimetic logger temperatures was similar to the accuracy of the theoretical model predictions of live Pisaster temperatures. This suggests that Pisaster do not have an active temperature-regulating mechanism because all mechanisms of heat transfer appear to be accounted for in the model. However, data for the comparison between the model and logger temperatures were only available for $4 \mathrm{~d}$, so a more thorough comparison is necessary to conclusively test this hypothesis.

The biomimetic data loggers developed in this study could be deployed extensively both within and among sites, and they provide an excellent tool for investigating patterns of thermal heterogeneity in this species. Theoretical models and biomimetic data loggers used in tandem offer an excellent means of exploring patterns of thermal stress in Pisaster when combined with data on the effects of temperature on physiological performance of predator and prey (Pincebourde et al. 2008), and are an important first step towards understanding the indirect effects of climate, and climate change, on intertidal ecosystems.

\section{Interplay of body temperature and intertidal height}

The deployment of the biomimetic data loggers at different tidal heights showed variation in body temperatures within the site across the natural vertical zonation range of Pisaster. As expected, the high logger consistently experienced the highest temperatures for all filtered daily maxima, with nearly half of the days having maximum temperatures $\geq 25^{\circ} \mathrm{C}$. Almost all of the daily minima for all loggers were below sea surface temperature, which shows that cooling is occurring during some of the low tides, often during nighttime. These loggers show the differences in body temperature at different tidal heights and illustrate how moving around in the intertidal can yield widely different temperatures for Pisaster.

As a mobile species, Pisaster has the ability to behaviorally thermoregulate to avoid heat stress. Many intertidal predators show little or no movement during low tide (e.g. Newell et al. 1971), and Pisaster in particular are inactive during low tide (Robles et al. 1995). Robles et al. (1995) found that Pisaster move upshore with the incoming tide to feed and then move downshore before the tide recedes again. They also found that Pisaster can move $>3 \mathrm{~m}$ vertically and $>10 \mathrm{~m}$ along 
the rock surface during a single tide before returning to low intertidal levels to rest during low tide. These findings seemingly contradict Paine's (1974) findings that Pisaster move at rates of $<4 \mathrm{~m} \mathrm{mo}^{-1}$; however, Paine's data were the result of a recapture experiment over a period of months and did not elucidate Pisaster movement over small timescales such as the span of a single tide. The sea stars may move considerably during a single tide, but they return to lower shore levels before the tide recedes. In Oregon, individual Pisaster have also been observed to stay hunched over patches of prey for multiple days without vertically migrating with the tides (Menge et al. 2002). However, the site used in this study was characterized by dominant cover of Fucus sp. in the lower and mid-intertidal and barnacles in the high intertidal. Therefore, Pisaster could not remain hunched over prey patches for days at a time or they would have been forced to remain in the high intertidal during low tide, which would cause temperature and desiccation stress. Pisaster are very mobile during high tide, and thus they could easily move to areas where the potential for reaching thermally stressful temperatures is decreased. The height reached in the lower intertidal may, at least partially, be determined by the body temperatures they reach during the previous day's low tide.

As demonstrated above, intertidal height has a large impact on Pisaster body temperature (Fig. 5). Therefore, the lower the Pisaster are in the intertidal zone, the lower their body temperatures will be during low tide. The results presented here suggest that the sea stars move lower in the intertidal, with some individuals possibly remaining in the subtidal zone, after hot days to avoid subsequent potentially thermally stressful temperatures; they stay higher in the intertidal after cool days.

The correlations between body temperature and number of Pisaster counted, and between percent change in body temperature from Day $n$ to Day $n+1$ and percent change in number of Pisaster counted from Day $n$ to Day $n+1$, were weak but significant. The weakness of the correlation could be attributed to the microhabitat variability of the site. Rather than all sea stars moving lower in the intertidal, many may attach to vertical surfaces or move into small cracks to avoid direct solar radiation while remaining at the same tidal height. These results suggest that acute aerial heat stress may have a greater impact on Pisaster distribution than chronic heat stress because the sea stars can behaviorally thermoregulate to avoid consecutive stress episodes.

An interesting next step of this research is to use the tools presented here to examine temperature differences between predator (Pisaster) and prey (Mytilus californianus). A heat budget model of $M$. californi- anus has already been developed (Helmuth 1998, Gilman et al. 2006), and these 2 models should be run in tandem to determine differential patterns of temperature and thermal stress across the 2 species. Such differences could have significant effects on the predator-prey interaction, which could, in turn, impact the community structure of the entire ecosystem. By continuing to combine ecological field studies with the model presented here, we are taking important steps in accurately predicting how this ecosystem will respond to climate change.

Acknowledgements. We thank Bamfield Marine Sciences Centre for providing logistical support and access to the sites used in this study. We also thank Huu-ay-aht First Nations for access to field sites. M. Lloyd and D. Salkoff provided assistance in the field. N. Feigley assisted with graphics. The manuscript was greatly improved with comments from S. Chintalapati, S. Pincebourde, K. A. Smith, S. E. Stancyk, L. Yamane, and 2 anonymous reviewers. Cloud cover data were obtained from the GEWEX GCIP data archive maintained by R. Pinker at the University of Maryland. Funding was provided by NASA Grant NNG04GE43G to B.H. and D.S.W., NOAA Grant NA04NOS4780264 to D.S.W. and B.H., and a Bamfield Marine Sciences Centre Graduate Research Scholarship to P.L.S.

\section{LITERATURE CITED}

Bell EC (1995) Environmental and morphological influences on thallus temperature and desiccation of the intertidal alga Mastocarpus papillatus Kützing. J Exp Mar Biol Ecol 191:29-55

Buckley BA, Owen ME, Hofmann GE (2001) Adjusting the thermostat: changes in the threshold induction temperature for heat shock protein genes in mussels from the genus Mytilus. J Exp Biol 204:3571-3579

Campbell GS (1977) An introduction to environmental biophysics. Springer-Verlag, New York

Connell JH (1961) The influence of interspecific competition and other factors on the distribution of the barnacle Chthamalus stellatus. Ecology 42:710-723

Connell JH (1972) Community interactions on marine rocky intertidal shores. Annu Rev Ecol Syst 3:169-192

Cosgrove BA, Lohmann D, Mitchell KE, Houser PR and others (2003) Land surface model spin-up behavior in the North American Land Data Assimilation System (NLDAS). J Geophys Res 108(D22):8845

Crisp DJ (1964) The effects of the severe winter of 1962-63 on marine life in Britain. J Anim Ecol 33:165-210

Crisp DJ, Southward AJ (1958) The distribution of intertidal organisms along the coasts of the English Channel. J Mar Biol Assoc UK 37:157-208

> Davenport J, Davenport JL (2005) Effects of shore height, wave exposure and geographical distance on thermal niche width of intertidal fauna. Mar Ecol Prog Ser 292: $41-50$

> Davis AJ, Jenkinson LS, Lawton JH, Shorrocks B, Wood S (1998a) Making mistakes when predicting shifts in species range in response to global warming. Nature 391:783-786

> Davis AJ, Lawton JH, Shorrocks B, Jenkinson LS (1998b) Individualistic species responses invalidate simple physiological models of community dynamics under global environmental change. J Anim Ecol 67:600-612 
Denny MW (1993) Air and water. Princeton University Press, Princeton, NJ

Denny MW, Wethey DS (2002) Physical processes that generate patterns in marine communities. In: Bertness MD, Gaines SD, Hay ME (eds) Marine community ecology. Sinauer Associates, Sunderland, MA, p 1-37

$>$ Denny MW, Harley CDG (2006) Hot limpets: predicting body temperature in conductance-mediated thermal system. J Exp Biol 209:2409-2419

Fitzhenry T, Halpin PM, Helmuth B (2004) Testing the effects of wave exposure, site, and behavior on intertidal mussel body temperatures: applications and limits of temperature logger design. Mar Biol 145:339-349

Flater D (2005) XTide: harmonic tide clock and tide predictor. www.xtide.com/xtide/index.html

Foster BA (1969) Tolerances of high temperatures by some intertidal barnacles. Mar Biol 4:326-332

Foster BA (1971) On the determinants of the upper limit of intertidal distribution of barnacles (Crustacea: Cirripedia). J Anim Ecol 40:33-48

Gates DM (1980) Biophysical ecology. Springer-Verlag, New York

Gilman SE, Wethey DS, Helmuth B (2006) Variation in the sensitivity of organismal body temperature to climate change over local and geographic scales. Proc Natl Acad Sci USA 103:9560-9565

Helmuth BST (1998) Intertidal mussel microclimates: predicting the body temperature of a sessile invertebrate. Ecol Monogr 68:29-52

Helmuth B (1999) Thermal biology of rocky intertidal mussels: quantifying body temperatures using climatological data. Ecology 80:15-34

Helmuth BST, Hofmann GE (2001) Microhabitats, thermal heterogeneity, and patterns of physiological stress in the rocky intertidal zone. Biol Bull 201:374-384

- Helmuth B, Harley CDG, Halpin PM, O'Donnell M, Hofmann GE, Blanchette CA (2002) Climate change and latitudinal patterns of intertidal thermal stress. Science 298: 1015-1017

- Helmuth B, Mieszkowska N, Moore P, Hawkins SJ (2006a) Living on the edge of two changing worlds: forecasting the responses of rocky intertidal ecosystems to climate change. Annu Rev Ecol Evol Syst 37:373-404

Helmuth B, Broitman BR, Blanchette CA, Gilman S and others (2006b) Mosaic patterns of thermal stress in the rocky intertidal zone: implications for climate change. Ecol Monogr 76:461-479

Holman J (1986) Heat transfer. McGraw-Hill, New York

$>$ Hutchins LW (1947) The bases for temperature zonation in geographical distribution. Ecol Monogr 17:325-335

Idso S (1981) A set of equations for full spectrum and 8-mu-m to $14-\mathrm{mu}-\mathrm{m}$ and $10.5-\mathrm{mu}-\mathrm{m}$ to $12.5-\mathrm{mu}-\mathrm{m}$ thermalradiation from cloudless skies. Water Resour Res 17:295-304

Kingsolver JG (1979) Thermal and hydric aspects of environmental heterogeneity in the pitcher plant mosquito. Ecol Monogr 49:357-376

MacArthur RH (1972) Geographical ecology: patterns in the distribution of species. Princeton University Press, Princeton, NJ

Menge BA, Sanford E, Daley BA, Freidenburg TL, Hudson G, Lubchenco J (2002) An inter-hemispheric comparison of bottom-up effects on community structure: insights revealed using the comparative-experimental approach. Ecol Res 17:1-16

Monteith JL, Unsworth MH (1990) Principles of environmental physics, 2nd edn. Edward Arnold, London

> Mustin K, Sutherland WJ, Gill JA (2007) The complexity of predicting climate-induced ecological impacts. Clim Res
35:165-175

National Oceanic and Atmospheric Administration (2005) NOAA CoastWatch Program. Available at: coastwatch. noaa.gov. Accessed February 22, 2005

Newell RC, Pye VI, Ahsanullah M (1971) Factors affecting the feeding rate of the winkle Littorina littorea. Mar Biol 9: 138-144

Paine RT (1966) Food web complexity and species diversity. Am Nat 100:65-76

Paine RT (1974) Intertidal community structure: experimental studies on the relationship between a dominant competitor and its principal predator. Oecologia 15:93-120

> Paine RT (1976) Size-limited predation: an observational and experimental approach with the Mytilus-Pisaster interaction. Ecology 57:858-873

Paine RT (1994) Marine rocky shores and community ecology: an experimentalist's perspective. Exellence in ecology book series. Inter-Research, Oldendorf/Luhe

Pincebourde S, Sanford E, Helmuth B (2008) Weather conditions during low tide alter the feeding performance of a top intertidal predator. Limnol Oceanogr 53:1562-1573

> Pinker RT, Tarpley JD, Laszlo I, Mitchell KE and others (2003) Surface radiation budgets in support of the GEWEX Continental-Scale International Project (GCIP) and the GEWEX Americas Prediction Project (GAPP), including the North American Land Data Assimilation System (NLDAS) project. J Geophys Res 108(D22):8844

Place SP, O'Donnell MJ, Hofmann GE (2008) Gene expression in the intertidal mussel Mytilus californianus: physiological response to environmental factors on a biogeographic scale. Mar Ecol Prog Ser 356:1-14

$>$ Porter WP, Gates DM (1969) Thermodynamic equilibria of animals with environment. Ecol Monogr 39:227-244

> Rand DN, Spaeth PS, Sackton TB, Schmidt PS (2002) Ecological genetics of Mpi and Gpi polymorphisms in the acorn barnacle and the spatial scale of neutral and non-neutral variation. Integr Comp Biol 42:825-836

Ricketts EF, Calvin J, Hedgpeth JW (revised by Phillips DW) (1994) Between Pacific tides, 5th edn. Stanford University Press, Palo Alto, CA

> Robles C, Sherwood-Stephens R, Alvarado M (1995) Responses of a key intertidal predator to varying recruitment of its prey. Ecology 76:565-579

Sagarin RD, Gaines SD (2002) Geographical abundance distributions of coastal invertebrates: using one-dimensional ranges to test biogeographic hypotheses. J Biogeogr 29: 985-997

Sagarin RD, Somero GN (2006) Complex patterns of expression of heat-shock protein 70 across the southern biogeographical ranges of the intertidal mussel Mytilus californianus and snail Nucella ostrina. J Biogeogr 33:622-630

Sagarin RD, Barry JP, Gilman SE, Baxter CH (1999) Climaterelated change in an intertidal community over short and long time scales. Ecol Monogr 69:465-490

Sanford E (1999) Regulation of keystone predation by small changes in ocean temperature. Science 283:2095-2097

> Sanford E (2002a) Water temperature, predation, and the neglected role of physiological rate effects in rocky intertidal communities. Integr Comp Biol 42:881-891

Sanford E (2002b) The feeding, growth, and energetics of two rocky intertidal predators (Pisaster ochraceus and Nucella canaliculata) under water temperatures simulating episodic upwelling. J Exp Mar Biol Ecol 273:199-218

> Somero GN (2002) Thermal physiology and vertical zonation of intertidal animals: optima, limits, and costs of living. Integr Comp Biol 42:780-789

Southward AJ (1955) On the behaviour of barnacles. I. The 
relation of cirral and other activities to temperature. J Mar Biol Assoc UK 34:403-422

Southward AJ (1958) Note on the temperature tolerances of some intertidal animals in relation to environmental temperatures and geographical distribution. J Mar Biol Assoc UK 37:49-66

Southward AJ, Hawkins SJ, Burrows MT (1995) Seventy years' observations of changes in distribution and abundance of zooplankton and intertidal organisms in the western English Channel in relation to rising sea temperature. J Therm Biol 20:127-155

Stenseng E, Braby CE, Somero GN (2005) Evolutionary and acclimation-induced variation in the thermal limits of heart function in congeneric marine snails (genus Tegula): implications for vertical zonation. Biol Bull 208:138-144

Stillman JH (2003) Acclimation capacity underlies susceptibility to climate change. Science 301:65

Tennessee Valley Authority (1972) Heat and mass transfer between a water surface and the atmosphere. Water Resources Laboratory Report 14, Tennessee Valley Authority, Norris, TN

- Tracy CR (1976) A model of the dynamic exchanges of water and energy between a terrestrial amphibian and its environment. Ecol Monogr 46:293-326

Wethey DS (1983) Geographic limits and local zonation: the barnacles Semibalanus (Balanus) and Chthamalus in New England. Biol Bull 165:330-341

Wethey DS (1984) Sun and shade mediate competition in the barnacles Chthamalus and Semibalanus: a field experiment. Biol Bull 167:176-185

> Wethey DS (2002) Biogeography, competition, and microclimate: the barnacle Chthamalus fragilis in New England. Integr Comp Biol 42:872-880

> Wethey DS, Woodin SA (2008) Ecological hindcasting of biogeographic responses to climate change in the European intertidal zone. Hydrobiologia 606:139-151

Appendix 1.

\begin{abstract}
Theoretical approach
A heat budget model is an equation that calculates the heat energy stored in an animal by adding the sources and sinks of heat into and out of the animal. The energy stored determines temperature, and all sources, sinks, and stores of heat must be balanced at all times (Porter \& Gates 1969, Campbell 1977, Gates 1980). Heat energy is transferred via 5 general mechanisms: convection $\left(Q_{\text {conv }}\right)$, conduction $\left(Q_{\text {cond }}\right)$, short-wave solar radiation $\left(Q_{\text {sol }}\right)$, long-wave infrared radiation $\left(Q_{\mathrm{rad}}\right)$, and evaporative heat loss $\left(Q_{\text {evap }}\right)$ (see Fig. $1)$; thus, the sum of these fluxes of heat must equal the stored heat in the animal:

$$
Q_{\text {stored }}=Q_{\text {conv }} \pm Q_{\text {cond }} \pm Q_{\text {sol }} \pm Q_{\text {rad }}-Q_{\text {evap }}
$$

For an explanation of each of the methods of heat flux, see Porter \& Gates (1969) or Denny \& Wethey (2000).

The heat flux equations were combined and expanded to create an unsteady state heat budget model for Pisaster ochraceus (hereafter Pisaster) which calculates body temperature under changing environmental conditions in the field. The model developed in this study calculates temperature through three $1 \mathrm{~cm}$ deep layers that represent the sea star, and fifty $1 \mathrm{~cm}$ deep layers that represent the underlying rock. During high tide, the model sets Pisaster temperature and substratum surface temperature equal to sea surface temperature. At low tide, the following energy balance is solved for surface temperature $\left(T_{\mathrm{s}}\right)$ :

the emissivity of the sea star surface, $\lambda$ is the latent heat of evaporation, $h_{\mathrm{e}}$ is the evaporative heat transfer coefficient, and $v p_{\text {air }}$ and $\mathrm{vp}_{\mathrm{s}}$ are the water vapor pressures of the air and at the sea star surface. Once the surface temperature was calculated from the energy balance, conduction into the sea star and rock substratum was modeled using an explicit (forward in time, centered in space) finite difference approximation to the heat conduction equation.

Sea star temperature at the $1 \mathrm{~cm}$ layer was used to represent Pisaster body temperatures. However, it should be noted that, based on field measurements, body temperature in Pisaster varies along different parts of the body, in particular between the central disk and the arms. Estimates of body temperature thus represent temperatures in the central disk. For values of parameters used in the model, see Table 1. A program was written in $\mathrm{C}$ to perform the calculations, which was modified from the model of Gilman et al. (2006).

The theoretical model developed in the present study used an approximation that underestimated incoming longwave radiation, so an empirically derived multiplier of 0.789 was used in the equations containing long-wave emissivity terms to correct for this difference. This multiplier was calculated by running the model with a range of emissivity values to quantify how much the model was underestimating long-wave radiation, and then dividing the emissivity value of Pisaster of 0.95, which is in the recorded range measured by Carrington et al. (unpubl. data), by the emissivity value that yielded model results that best fit the actual Pisaster temperature data $(0.75)$.
\end{abstract}

$$
\begin{aligned}
& -k\left(T_{\mathrm{s}}-T_{1}\right) / \Delta z=h_{\mathrm{c}}\left(T_{\text {air }}-T_{\mathrm{s}}\right)+\alpha q_{\mathrm{solar}}+ \\
& \sigma\left(\varepsilon_{\text {atm }} T_{\text {air }}{ }^{4}-\varepsilon_{\mathrm{s}} T_{\mathrm{s}}^{4}\right)+\lambda h_{\mathrm{e}}\left(\mathrm{vp}_{\mathrm{air}}-\mathrm{vp}_{\mathrm{s}}\right)
\end{aligned}
$$

where $k$ is thermal conductivity, $T_{\mathrm{s}}$ is surface temperature, $T_{1}$ is the temperature 1 layer deep in the sea star, $\Delta z$ is layer thickness, $h_{\mathrm{c}}$ is the heat transfer coefficient, $T_{\text {air }}$ is air temperature, $\alpha$ is short-wave solar absorptivity of the surface of the sea star, $q_{\text {solar }}$ is solar radiation, $\sigma$ is the Stefan-Boltzmann constant, $\varepsilon_{\mathrm{atm}}$ is the emissivity of the atmosphere, $\varepsilon_{\mathrm{s}}$ is

\section{Operation of model}

The model requires appropriate spin-up time with environmental data to generate accurate predictions. Because of the method of data collection, the model was run on a daily basis, rather than continuously, so a separate input dataset 
Appendix 1 (continued)

of microclimate data with spin-up was created/compiled for each day. Input datasets began with $2 \mathrm{~h}$ of submergence during high tide to allow the model to spin-up, followed by the entire duration of the low tide. The Pisaster were exposed for varying periods of time before the weather station was set up and recording of body temperatures began. The period of exposure before data collection began each day was calculated using tide tables generated by the program XTide, which uses NOAA tidal prediction algorithms (Flater 2005). Weather data from the first recorded time step of each day were used for all time steps of exposure prior to when data collection began (lead time). If the sun rose after the sea stars were exposed but before data collection began, solar radiation was assumed to be $0 \mathrm{~W} \mathrm{~m}^{-2}$ until sunrise and was assumed to increase linearly until the first recorded time step value.

\section{Data assimilation method}

We used a process of data assimilation (see Cosgrove et al. 2003) to correct for the differing initial temperatures and to compare the time-series trajectories (i.e. the rates of change of temperature) of the model output to those of Pisaster body temperatures. The model was run for each day as described above, and then the first recorded average Pisaster temperature was subtracted from the model temperature at the same time step. This initial difference in temperatures was then subtracted from the model output temperatures for the entire day. This correction was repeated for all days for which data were available.

\section{Structure of program code}

Program initialization

1. All layers in the Pisaster and underlying rock are initialized to sea surface temperature.

The program runs through a loop with the following steps when the tide is low:

2. Solve energy balance at surface for skin temperature (Eq. 2)

3. Conduct heat through the Pisaster and the underlying rock using the skin temperature from Step 1

4. Repeat
The program does the following calculations when the tide is high:

1. Use sea surface temperature to determine Pisaster temperature and the surface temperature of the underlying rock. This is called a 'fixed boundary condition'

2. Conduct heat through the Pisaster and the underlying rock using the temperatures from Step 1

3. Repeat

The time step $\Delta t$ for the heat conduction finite difference calculations is $10 \mathrm{~s}$.

\section{Details of heat conduction equations}

The heat conduction equation states that the rate of change of temperature with respect to time is proportional to the second spatial derivative of temperature and the thermal diffusivity $(\kappa)$.

$$
\mathrm{d} T / \mathrm{d} t=\kappa \partial^{2} T / \partial z^{2}
$$

The finite difference approximation of this partial differential equation uses a finite spatial scale $\Delta z$, a finite temporal scale $\Delta t$, and finite temperature differences $\Delta T$ :

$$
\Delta T / \Delta t=\kappa \Delta^{2} T / \Delta z^{2}
$$

The finite difference approximation to the dynamics of temperature states that the temperature at depth $z$ and time $t+1[T(z, t+1)]$ is determined from the temperature at depth $z$ and time $t[T(z, t)]$ plus the rate of change at depth $z$ and time $t[\Delta T(z, t)]$, multiplied by the length of the time step $\Delta t$.

$$
T(z, t+1)=T(z, t)+\Delta T(z, t) \Delta t
$$

The change in temperature at depth $z$ and time $t$ is proportional to the second derivative of temperature with spatial position (Eq. 4). The second derivative of temperature with respect to spatial position was approximated with a forward in time, centered in space, explicit equation (Holman 1986):

$\Delta T(z, t+1)^{2} / \Delta z^{2}=[T(z+1, t)-2 T(z, t)+T(z-1, t)] / \Delta z^{2}$

Substituting Eqs. (4) \& (6) into Eq. (5), we obtain the finite difference approximation to the heat conduction equation:

$T(z, t+1)=T(z, t)+\kappa \Delta t[T(z+1, t)-2 T(z, t)+t(z-1, t)] / \Delta z^{2}$
Editorial responsibility: Richard Osman, Edgewater, Maryland, USA
Submitted: February 7, 2008; Accepted: August 6, 2008

Proofs received from author(s): December 5, 2008 